\title{
A
}

\section{Bandgap Alteration of Transparent Zinc Oxide Thin Film with Mg Dopant}

\author{
M. Salina ${ }^{\dagger}$ and R. Ahmad \\ NANO Elec Tronic Centre, Faculty of Electrical Engineering, Universiti Teknologi MARA, 40450 Shah Alam, Selangor, Malaysia
}

\author{
A. B. Suriani \\ NANO SciTech Centre, Institute of Sciences, Universiti Teknologi MARA, 40450 Shah Alam, Selangor, Malaysia
}

\author{
M. Rusop \\ NANO ElecTronic Centre, Faculty of Electrical Engineering and NANO SciTech Centre, Institute of Sciences, Universiti \\ Teknologi MARA, 40450 Shah Alam, Selangor, Malaysia
}

Received November 3, 2011; Revised January 5, 2012; Accepted January 21, 2012

\begin{abstract}
We have successfully demonstrated a bandgap alteration of transparent zinc oxide (ZnO) thin film with Mg dopant by using sol-gel spin coating technique. By increasing the dopant from 0 to 30 atomic percent (at.\%), a decrement value in the cutoff is observed, where the absorption edge shifts continuously to the shorter wavelength side, towards $300 \mathrm{~nm}$. This resulted in a significant bandgap increment from 3.28 to $3.57 \mathrm{eV}$. However, the transmittance of the thin film at 350-800 nm gradually downgraded, from 93 to $80 \%$ which is most probably due to the grain size that becomes bigger, and it also affected the electrical properties. The decrement from 45 to $0.05 \mathrm{~mA}$ at $+10 \mathrm{~V}$ was observed in the I-V characteristics, concluding the significant relationship; where higher optical bandgap materials will exhibit lower conductivity. These findings may be useful in optoelectronics devices.
\end{abstract}

Keywords: ZnO, MgZnO, Optical band gap, Thin film

\section{INTRODUCTION}

Recently, many researchers gained the interest to study transparent zinc oxide $(\mathrm{ZnO})$ thin film semiconducting nanostructures. They were interested to study their potential properties and applications especially in field effect transistor (FET), light emitting diode, laser diode and other optoelectronic devices [1-5]. Owing to a direct and wide bandgap of $3.3 \mathrm{eV}$ at room temperature and its ability to alter or tailor the bandgap makes $\mathrm{ZnO}$ to become a potential candidate for further exploration and study. Tailored materials are necessary to build many tech-

${ }^{\dagger}$ Author to whom all correspondence should be addressed: E-mail:ina1320@yahoo.com

Copyright $\odot 2012$ KIEEME. All rights reserved.

This is an open-access article distributed under the terms of the Creative Commons Attribution Non-Commercia

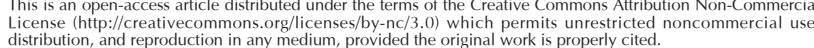

nologically important devices including field effect transistor in transparent electronics based [2-3]. Tailoring and altering the bandgap will affect the electrical behavior as well as other properties. This can be done through doping, alloying and heterostructures with some materials such as $\mathrm{Al}, \mathrm{Mn}$ and $\mathrm{Mg}$ [6-8]. Till date, $\mathrm{Mg}$ is the most popular dopant material as the ionic radii of $\mathrm{Mg}^{2+}$ and $\mathrm{Zn}^{2+}$ are nearly equal and so, this resulted in a very little lattice distortion when $\mathrm{Zn}$ ion is replaced by $\mathrm{Mg}$ ion $[8,9]$. However, there is a difficulty of tailoring the bandgap due to the immiscibility of the different crystal structures between $\mathrm{ZnO}$ (wurtzite) and MgO (rocksalt) [10]. Hence, many reports have come out with lots of technique in order to deposit MgZnO thin film and overcome that problem such as metal-organic vapour phase epitaxy (MOVPE) [11], molecular beam epitaxy (MBE) [12], RF magnetron co-sputtering [13], sol-gel [14], etc. Among all the deposition techniques, it is believed that sol-gel has got certain distinct advantages in the making of alloy oxides and doping. 
Besides being an easy and cheap operation, low processing temperatures lead to the easiness in the kinetics control and also in the minimization of chemical interaction between the material and the container wall. It also leads to an excellent compositional control. To be more significant, it also leads to an ability to achieve atomic scale mixing of individual components [14]. The growth of $\mathrm{MgZnO}$ thin film at high temperature and its physical properties, the electrical properties that are to be used as high-k dielectric material, and the effect of post annealing on a thin film has been reported earlier by Kim et al., Liang et al., and Meher et al., respectively [15-17]. However, none of them have emphasized the effect of those processes on the bandgap, which more or less reflects the electrical properties of MgZnO thin film as well as other properties.

Hence, in this paper, we present the bandgap alteration of transparent $\mathrm{ZnO}$ thin film by using $\mathrm{Mg}$ dopant. Moreover, we also present the growth of $\mathrm{Mg}_{\mathrm{x}} \mathrm{Zn}_{1-\mathrm{x}} \mathrm{O}(0.0<\mathrm{x}<0.3)$ thin film by using sol-gel spin coating technique, along with the electrical properties of the thin film. Theoretically, the bandgap of $\mathrm{MgZnO}$ can reach up to almost $8 \mathrm{eV}$ by tuning $\mathrm{Mg}$ content up to 100 at.\% [17]. However, structural transition from hexagonal wurtzite to a cubic structure could pose limitations near the mixed phase region [17]. Due to this reason, we limit our Mg content to only 30 at.\% in order to retain the wurtzite structure while altering the bandgap of the $\mathrm{ZnO}$ thin film.

\section{EXPERIMENTAL DETAILS}

The $\mathrm{Mg}_{\mathrm{x}} \mathrm{Zn}_{1-\mathrm{x}} \mathrm{O}(0<\mathrm{x}<0.3)$ thin film samples were prepared in a clean room on $2 \times 2 \mathrm{~cm}^{2}$ quartz substrate by using sol-gel method with a spin coating technique. Methanol and de-ionized water have been used for the purpose of cleaning before being rinsed with de-stilled water and dried with a nitrogen gun. Then, the substrate is ready to be used.

The starting materials that were used were zinc acetate dehydrate $\left[\mathrm{Zn}\left(\mathrm{CH}_{3} \mathrm{CO}\right)_{2} \cdot 2 \mathrm{H}_{2} \mathrm{O}\right]$, together with solvent, 2-methoxyethanol $\left[\mathrm{C}_{3} \mathrm{H}_{8} \mathrm{O}_{2}\right]$, mono-ethanolamine $\left[\mathrm{C}_{2} \mathrm{H}_{7} \mathrm{NO}\right]$ as a stabilizer and magnesium nitrate hexahydrate $\left[\mathrm{Mg}\left(\mathrm{NO}_{3}\right)_{2} \cdot 6 \mathrm{H}_{2} \mathrm{O}\right]$ as a dopant. For $0.4 \mathrm{M}$ solution, with $\mathrm{x}$ varies from 0.0 to 0.3 , the weightage of each chemical have been calculated before being mixed and stirred together in one solution respectively, as has been discussed elsewhere [1].

Before the deposition process, the solution was placed in a sonicator for about 30 minutes before being stirred and left at room temperature for $2 \mathrm{~h}$. The deposition of a thin film was done in a spin coater with $\mathrm{Ar}$ gas at $4 \mathrm{mbar}, 0.5 \mathrm{~s} / \mathrm{lit}$. The spin coater was programmed to rotate at $3000 \mathrm{rpm}$ for $60 \mathrm{sec}$. During rotation, 10 drops sol was dropped onto the substrate. Then, each layer was pre heated at $150{ }^{\circ} \mathrm{C}$ for $10 \mathrm{~min}$. Annealing process took place after the completion of all those 5 layers at $500^{\circ} \mathrm{C}$ for $1 \mathrm{~h}$. This process was repeated for $\mathrm{x}=0.1,0.2$, and 0.3 .

The surface morphology of the thin film has been studied by using field emission scanning electron microscopy (FESEM, ZEISS Supra 40VP). The optical properties were observed by UV-VIS Nir spectrophotometer (Varian Cary 5000) and photoluminescence (PL) (Horiba Jobin Yvon-79 DU420A-OE-325) spectrometer in order to calculate the band gap. Finally, the electrical properties of each sample were analyzed by using Keithley 2400 I-V measurement system.

\section{RESULTS AND DISCUSSION}

The surface morphologies of $\mathrm{Mg}_{\mathrm{x}} \mathrm{Zn}_{1-\mathrm{x}} \mathrm{O}(0.0<\mathrm{x}<0.3)$ thin films were observed. As shown in Fig. 1(a), the small particles of zinc
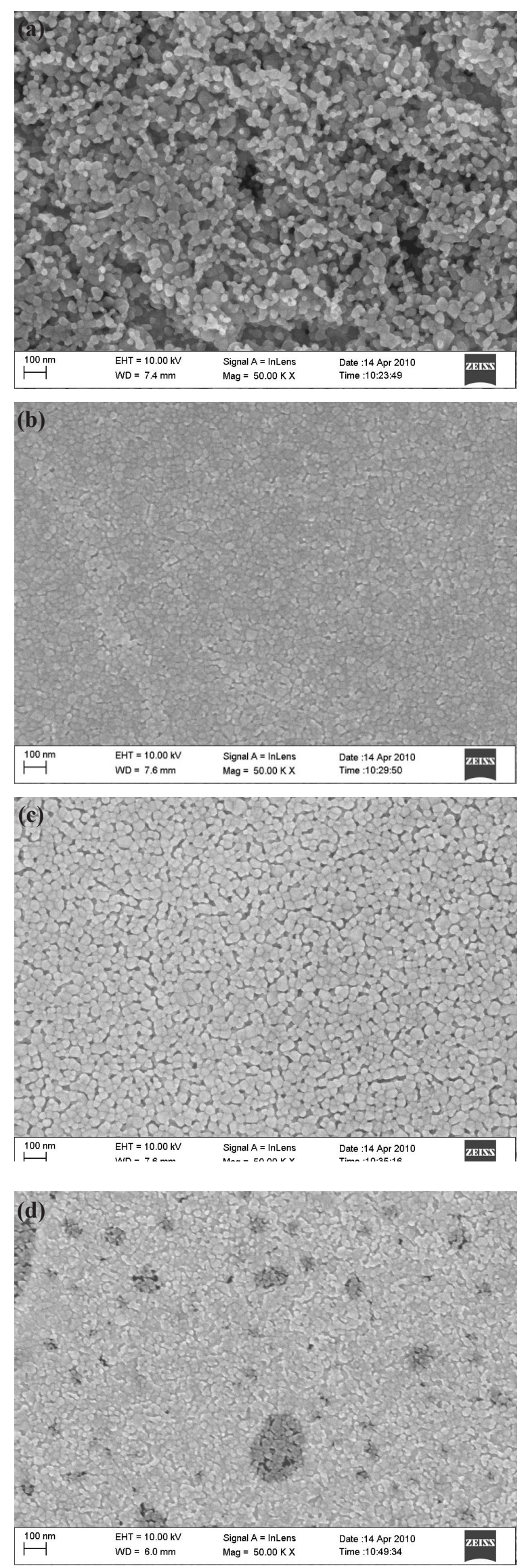

Fig. 1. Surface morphology of (a) $\mathrm{ZnO}$, (b) $\mathrm{Mg}_{0.1} \mathrm{Zn}_{0.9} \mathrm{O}$, (c) $\mathrm{Mg}_{0.2} \mathrm{Zn}_{0.8} 0$, (d) $\mathrm{Mg}_{0.3} \mathrm{Zn}_{0.7} 0$ thin film. 


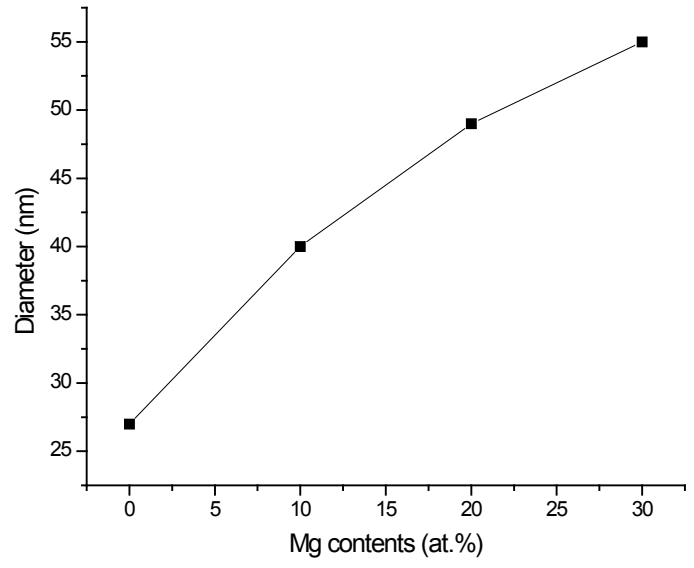

Fig. 2. Diameter size of $\mathrm{Mg}_{\mathrm{x}} \mathrm{Zn}_{1-\mathrm{x}} \mathrm{O}(0.0<\mathrm{x}<0.3)$ nanoparticles.

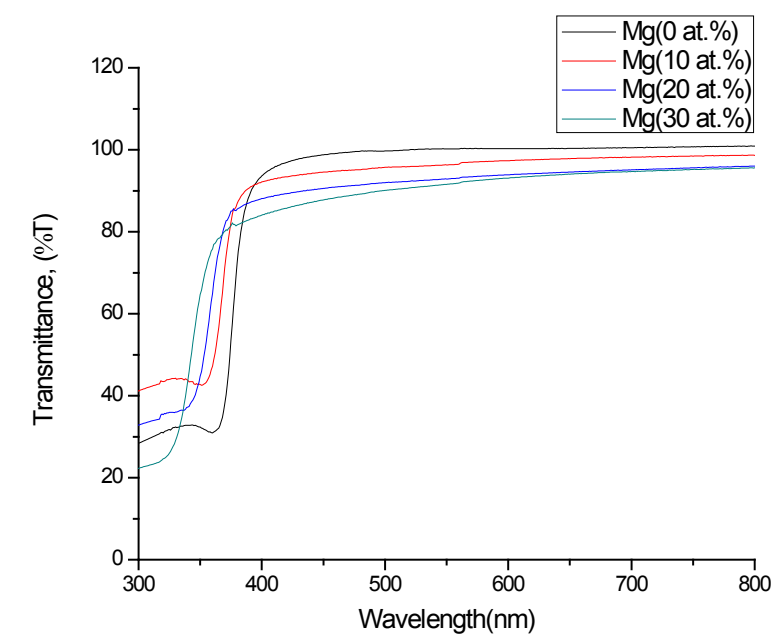

Fig. 3. Optical transmittance spectra of $\mathrm{Mg}_{\mathrm{x}} \mathrm{Zn}_{1-\mathrm{x}} \mathrm{O}(0.0<\mathrm{x}<0.3)$ thin film.

oxide can be seen with an average diameter of $20 \mathrm{~nm}$. This grain size becomes bigger and the surface becomes rougher but more uniform when the atomic percentage of magnesium increased as depicted in Fig. 1(b), (c), and (d). This is due to the substitution of magnesium ion with zinc during the sol-gel process. The increment in the diameter size of $\mathrm{Mg}_{\mathrm{x}} \mathrm{Zn}_{1-\mathrm{x}} \mathrm{O}(0.0<\mathrm{x}<0.3)$ nanoparticles in the thin film has been presented in Fig. 2.

Figure 3 shows the optical transmittance spectra of $\mathrm{Mg}_{\mathrm{x}} \mathrm{Zn}_{1-\mathrm{x}} \mathrm{O}$ $(0.0<x<0.3)$ thin films in the wavelength range between 300 to $800 \mathrm{~nm}$. The transparency properties of all thin films are more than $80 \%$ at a visible wavelength of $(350-800 \mathrm{~nm})$. It is observed that the transmittance has a tendency to decrease with Mg progressed. The highest transmittance edge was recorded at $93 \%$ for a sample with 0 at.\% of $\mathrm{Mg}$ while the lowest transmittance edge was obtained for 30 at.\% of Mg sample at $80 \%$, over the same wavelength. Reduction in the transmittance percentage is due to the progression of $\mathrm{Mg}$ in the thin film that enlarges the particle size and it slightly contributes to this phenomenon. The sharp absorption edges were observed around 329, 347, 359 and $367 \mathrm{~nm}$ for various $\mathrm{Mg}$ contents of 30, 20, 10 and 0 at.\%, respectively. It correspondents the direct transition of electron between the edges of the valence band and the conduction band.

Conversely, Fig. 4 shows the absorption coefficient, $\alpha$ of $\mathrm{Mg}_{\mathrm{x}} \mathrm{Zn}_{1-\mathrm{x}} \mathrm{O}(0.0<\mathrm{x}<0.3)$ thin films as a function of the wavelength

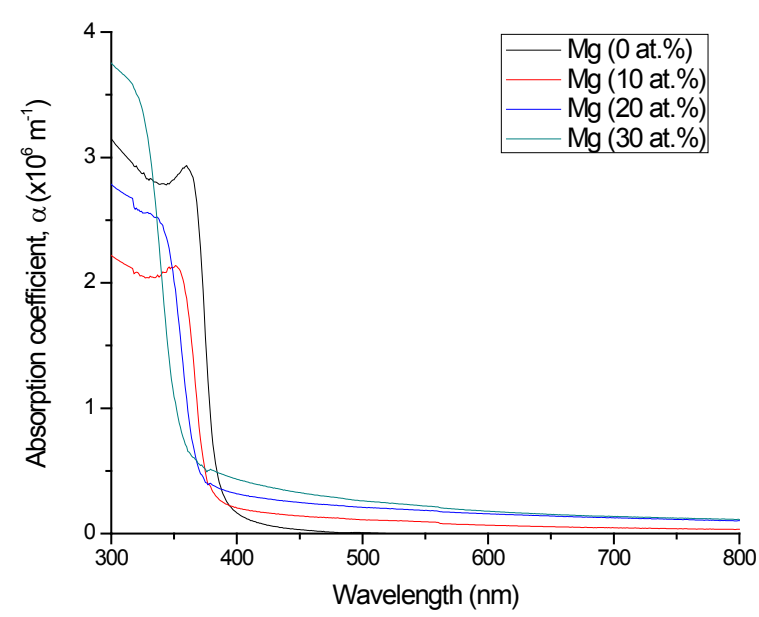

Fig. 4. Absorption coefficient of $\mathrm{Mg}_{\mathrm{x}} \mathrm{Zn}_{1-\mathrm{x}} \mathrm{O}(0.0<\mathrm{x}<0.3)$ thin film .

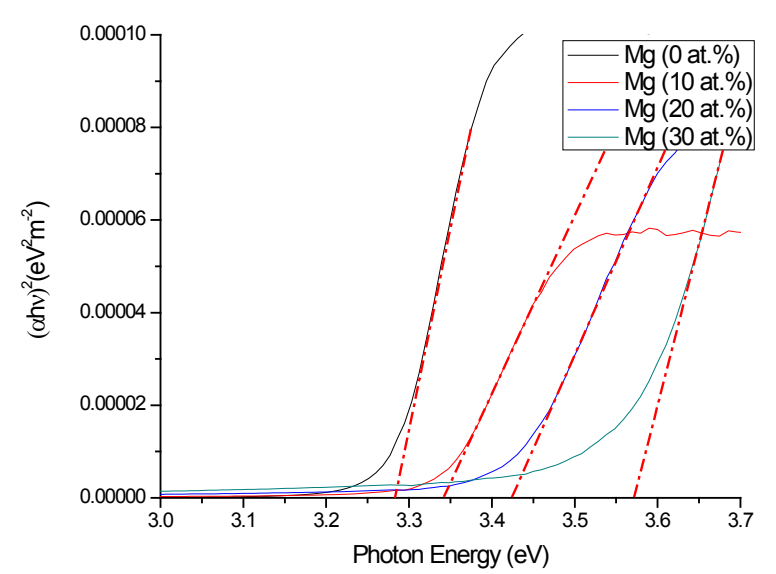

Fig. 5. Optical band gap estimation of $\mathrm{Mg}_{\mathrm{x}} \mathrm{Zn}_{1-\mathrm{x}} \mathrm{O}(0.0<\mathrm{x}<0.3)$ thin film using Tauc`s plot.

for various Mg contents. The absorption coefficient was calculated using the transmittance data, which has been presented previously. Lambert's Law has been applied to obtain the value of absorption coefficient at a respective wavelength with the Eq. (1) as follows:

$$
\alpha=\frac{1}{t} \ln \left(\frac{1}{T}\right)
$$

where, $t$ is the thickness and $T$ is the transmittance spectra of thin films. The result indicates that all films exhibit high absorption in the ultra violet (UV) range and low absorption in the visible and near the infra red (NIR) range. The absorption properties of $\mathrm{Mg}_{\mathrm{x}} \mathrm{Zn}_{1-\mathrm{x}} \mathrm{O}(0.0<\mathrm{x}<0.3)$ thin films in UV range are due to the behavior of $\mathrm{ZnO}$ intrinsic optical bandgap energy. It is estimated to be around $3.3 \mathrm{eV}$ where, the transmittance edge was raised to approximately $370 \mathrm{~nm}$ [18]. Absorption coefficients in the UV region significantly increased with $\mathrm{Mg}$ progress. The result suggests improvement in the optical absorption in the UV region with Mg progress, which provides useful information especially in the optoelectronic devices and device fabrication.

Approximately, the bandgap alteration of the thin film can be deduced from Fig. 3. Here, it evidently shows that changes in the absorption edges are in parallel with the Mg progressed in the thin film. In order to appropriately estimate the optical bandgap, 


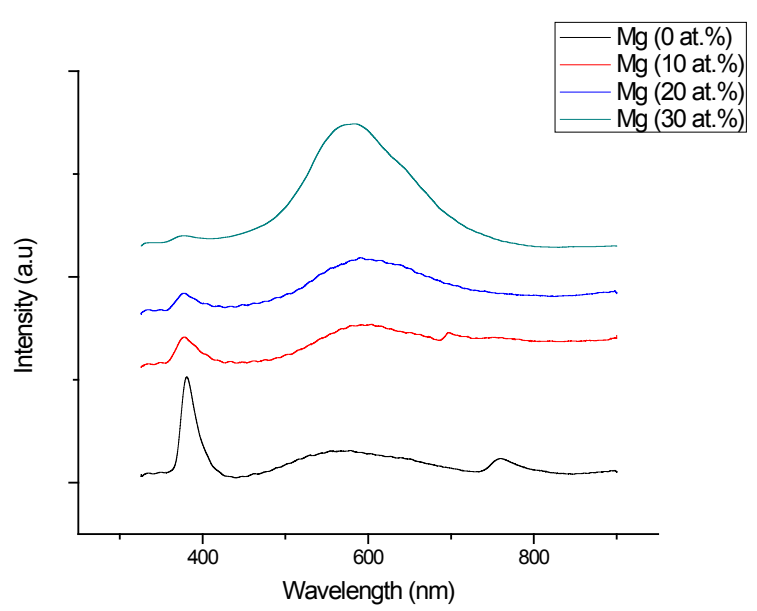

Fig. 6. PL spectra of $\mathrm{Mg}_{\mathrm{x}} \mathrm{Zn}_{1-\mathrm{x}} \mathrm{O}(0.0<\mathrm{x}<0.3)$ thin film.

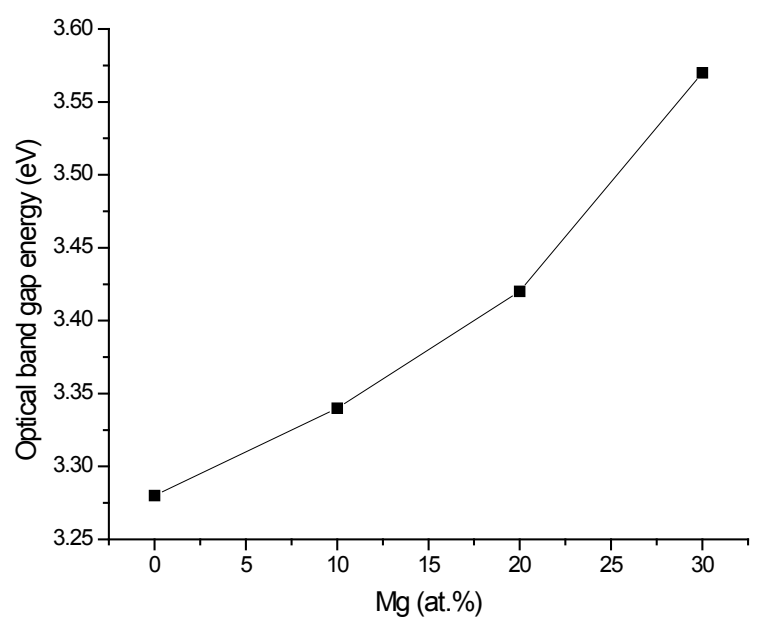

Fig. 7. Optical band gap energy of $\mathrm{Mg}_{\mathrm{x}} \mathrm{Zn}_{1-\mathrm{x}} \mathrm{O}(0.0<\mathrm{x}<0.3)$ thin film calculated by using Tauc`s plot.

the Tauc`s plot is used, as the following equation:

$$
\alpha h v=A\left(h v-E_{g}\right)^{1 / 2}
$$

where, $h$ is the Plank constant, $\mathrm{v}$ is the frequency of the incident photon, $\mathrm{A}$ is a constant depending on the electron-hole mobility and E_g is the optical bandgap energy. Fig. 5 shows the measured optical bandgap energy versus $\mathrm{Mg}$ progressed and it also shows a blue shift in the thin film. By extrapolating the linear part of the curve that intersects at the $\mathrm{x}$ axis, it will give the optical bandgap energy value. For 0 at.\% of Mg content which identical to $\mathrm{ZnO}$ thin film, the optical bandgap energy was 3.28 $\mathrm{eV}$, which is slightly higher compared to other reports $[19,20]$. With an increment in the Mg content up to 10 at.\%, the bandgap obtained increased to $3.34 \mathrm{eV}$. This was followed by 3.42 and 3.57 $\mathrm{eV}$ for 20 and 30 at.\% of $\mathrm{Mg}$ content, respectively. An increment of at least $0.3 \mathrm{eV}$ in the optical energy bandgap was obtained from 0 to 30 at.\% of $\mathrm{Mg}$ content in $\mathrm{ZnO}$ thin film. This evidently shows that the bandgap of $\mathrm{ZnO}$ thin film can be altered. To support this finding, the room temperature PL of the thin film in the range of $350-800 \mathrm{~nm}$ is presented in Fig. 6. The overall PL spectra shows an emission band with two obvious peaks, where the first peak, the UV peak which also called the emission or near band

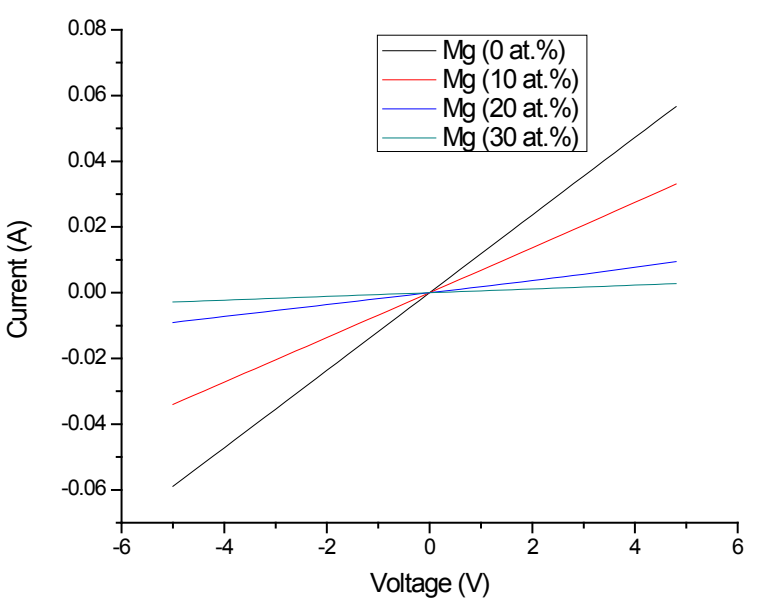

Fig. 8. Electrical properties of $\mathrm{Mg}_{\mathrm{x}} \mathrm{Zn}_{1-\mathrm{x}} \mathrm{O}(0.0<\mathrm{x}<0.3)$ thin film on $\mathrm{Pd}$ metal contact.

edge emission contributed to the free exciton recombination [18] The second broad peak, also known as the green emission corresponds to the recombination of a photon generated hole with an electron in singly ionized [18]. From the first peak, the optical bandgap can be simply calculated by using the relation,

$$
E=\frac{h c}{\lambda}
$$

where, $h$ is the plank constant and $\lambda$ is the wavelength. With this relation, the optical bandgap can simply be calculated by referring to the emission peak in the PL spectra. For 0 at.\% of $\mathrm{Mg}$, the emission peak falls at $380.50 \mathrm{~nm}$ and the optical badgap calculated was $3.26 \mathrm{eV}$. The increment of $0.02 \mathrm{eV}$ was observed when the $\mathrm{Mg}$ increased to 10 at.\% where the emission peak falls at $378.06 \mathrm{~nm}$. This was further increased, by reaching to $3.29 \mathrm{eV}$ $(377 \mathrm{~nm})$ for 20 at.\%, and it stops at $3.33 \mathrm{eV}(372.95 \mathrm{~nm})$ when the $\mathrm{Mg}$ content reached 30 at.\%. When compared to the previous value calculated by using Tauc`s plot, the values were slightly lower, but the increment patent was significantly noticed and it was identical. Thus, it can be concluded that the optical bandgap energy can be tuned, tailored and altered by using Mg dopant to the $\mathrm{ZnO}$ thin film.

Further investigation on electrical properties was carried out using Palladium metal contact. Fig. 8 shows the current-voltage (I-V) characteristics of $\mathrm{Mg}_{\mathrm{x}} \mathrm{Zn}_{1-\mathrm{x}} \mathrm{O}(0.0<\mathrm{x}<0.3)$ thin film where it reveals the decrement of the thin film conductivity that is in parallel to the Mg progress. At $4 \mathrm{~V}$, the current flow for 0 at.\% of Mg was $45 \mathrm{~mA}$ and it decreased to $24 \mathrm{~mA}$ when the Mg content increased to 10 at.\%. This was further decreased to 6 and $0.05 \mathrm{~mA}$ for 20 and 30 at.\% of $\mathrm{Mg}$, respectively. This was probably due to the existence of more $\mathrm{Mg}$ ion in the thin film that increased the resistivity. This request for more voltage to be supplied, so that there is enough energy for the electron to jump from the valence band to the conduction band. When the I-V characteristics were analyzed in parallel to the optical band gap properties, a significant relationship can be concluded. A material with higher optical bandgap will exhibit a lower conductivity. This is in parallel to the statement stated by others $[16,21]$.

When the four-point probe measurement took place, the reading shows an increasing value of sheet resistance with an increasing number of magnesium ions in the thin film. This is probably due to the widening of the energy bandgap with more magnesium ions to substitute the zinc oxide [16]. 


\section{CONCLUSIONS}

In summary, the physical, optical and electrical properties of $\mathrm{Mg}_{\mathrm{x}} \mathrm{ZnO}_{1-\mathrm{x}}(0.0<\mathrm{x}<0.3)$ thin film for FET applications were studied. Sol-gel spin coating technique was used to deposit $\mathrm{Mg}_{\mathrm{x}} \mathrm{ZnO}_{1}$ ${ }_{x}(0.0<x<0.3)$ thin film. The grain size of the thin film increased when the number of magnesium ions increased. It becomes rougher and the resistivity becomes higher. By increasing the dopant from 0 to 30 at.\%, the decrement value in the cutoff of each sample was observed, where the absorption edge shifts continuously to the shorter wavelength side towards $300 \mathrm{~nm}$, which results in a significant different bandgap being calculated. This shows a linear increment from 3.38 to $3.8 \mathrm{eV}$. However, the transmittance of the thin film at $350-800 \mathrm{~nm}$ is gradually downgraded, most probably due to the grain size which becomes bigger. It is proportional to the progression of the $\mathrm{Mg}$ dopant. The electrical property is strongly dependent on the structure size and density of the MgZnO thin films.

\section{ACKNOWLEDGEMENT}

The author was grateful with the support and would like to thank Ministry of Higher Education thru Fundamental Research Science Grant (Project Code: 600-RMI/ST/FRGS/ 5/3/Fst (34/2011)) for the funding.

\section{REFERENCES}

[1] M. Salina, M. Z. Sahdan, N. F. Jusoh, R. A. Kadir, and M.Rusop, Proceeding of ICEDSA2011, 423 (2011) [DOI: 10.1109/ICEDSA.2010.5503027].

[2] S. Chiaria, M. Goano, and E. Belloti, J. Quant. Elec. 47, 661 (2011) [DOI: 10.1109/JQE.2011.2104940].

[3] H. K. Liang, S. F. Yu, and H. Y. Yang, App. Phys. Lett. 97, 241107 (2010) [DOI: 10.1063/1.3527922].

[4] A. E. Rakhshani, J. Appl. Phys. 108, 094502 (2010) [DOI: 10.1063/1.3490622].
[5] A. B. Djurisic, A. M. C. Ng, and X. Y. Chen, Prog. Quant. Elec. 34 191 (2010) [DOI: 10.1016/j.quantelec.2010.04.001].

[6] T. Oshio, K. Masuko, A. Ashida, T. Yosgimura, and N. Fujimura, J. App. Phys. 103, 093717 (2010) [DOI: 10.1063/1.2905315].

[7] L. M. Li, Z. F. Du, and T. H. Wang, Sens. Act. B:Chem. 147, 165 (2010) [DOI: 10.1016/jsnb.2009.12.058].

[8] T. -H. Fang, S. -H. Kang, J. All. Comp. 492, 536 (2010) [DOI: 10.1016/.jallcom.2009.11.168].

[9] M. Ghosh,and A. Raychaudhuri, Trans. Nanotech. 10, 555 (2011) [DOI: 10.1109/TNANO.2010.2050899].

[10] S. B. Zhang, S. -H. Wei, A. Shunger, Phys. Rev. B, 63, 075205 (2001) [DOI: 10.1103/PhysRevB.63.075205].

[11] P. Kuznetsov, V. Lusanov, G. Yakushcheva, V. Jitov, L. Zakharov, I. Kotelyanskii, and V. Kozlovsky, IOP Conf. Ser.: Mater. Sci. Eng. 8, 012040 (2010) [DOI: 10.1088/1757-899X/8/1/012040].

[12] A. El-Shaer, A. Che Mofor, A. Bakin, M. Kreye, A. Waag, Superlattices and Microstructures, 38, 265 (2005) [DOI: 10.1016/ j.spmi.2005.08.025].

[13] I.-S. Kim, S. -H. Jeong, S. S. Kim, and B. -T. Lee, Semicond. Sci. Technol. 19, 29 (2004) [DOI: 10.1088/0268-1242/19/3/L06].

[14] C. H. Chia, Y. J. Lai, T. C. Han, J. W. Chiou, Y. M. Hu, and W. C. Chou, Appl. Phys. Lett. 96, 081903 (2010) [DOI: 10.1063/1.3327338].

[15] Y. Y. Kim, C. H. An, H. K. Cho, J. H. Kim, H. S. Lee, E. S. Jung, H. S. Kim,Thin Solid Films 516, 5602 (2008) [DOI: 10.1016/ j.tsf.2007.07.108].

[16] J. Liang, H. Wu, N. Chen, and T. Xu, Semicond. Sci. Technol. 20, L15 (2005) [DOI: 10.1088/0268-1242/20/5/L01]

[17] S. R. Meher, K. P. Biju and M. K. Jain, J. Sol-Gel Sci. Tech.52, 228 (2009) [DOI: 10.1007/s10971-009-2032-0]

[18] H. Li, J. Wang, H. Liu, C. Yang, H. Xu, X. Li, and H. Cui, Vacuum 77, 57 (2004) [DOI: 10.1016/j.vacuum.2004.08.003]

[19] S. T. Tan, B. J. Chen, X. W. Sun, W. J. Fan, H. S. Kwok, X. H. Zhang, and S. J. Chua, J. Appl. Phys. 98, 013505 (2005) [DOI: 10.1063/1.1940137].

[20] Y. Zhang, H. Jia, P. Li, F. Yang, and Z. Zheng, Opt. Comm. 284, 236 (2011) [DOI:10.1016/j.optcomm.2010.08.084].

[21] A. Kaushal, and D. Kaur, Sol. En. Mater. Sol. Cells 93, (2009) [DOI: 10.1016/j.solmat.2008.09.039]. 